\title{
Perancangan Online Examination System di Universitas Klabat Berbasis Web
}

\author{
Oktoverano H. Lengkong ${ }^{1}$, Christian Monintja ${ }^{2}$ \\ ${ }^{1}$ Program Studi Sistem Informasi, ${ }^{2}$ Program Studi Informatika \\ ${ }^{1,2}$ Fakultas Ilmu Komputer, Universitas Klabat \\ E-mail: ${ }^{1}$ oktoverano@unklab.ac.id, ${ }^{2}$ monintjac@gmail.com
}

\begin{abstract}
Abstrak
Media pengerjaan ujian yang diterapkan pada bidang pendidikan umumnya adalah kertas, pensil, atau pulpen. Penggunaan kertas dan alat tulis dapat memakan biaya serta waktu penyelenggaraan ujian, yaitu dalam penyajian soal maupun pengolahan nilai. Masalah lain yang dihadapi berupa meningkatnya konsumsi kertas secara global pada setiap tahunnya. Universitas Klabat merupakan salah satu institusi yang masih menggunakan cara konvensional dalam menyelenggarakan ujian, yaitu sistem pemeriksaan ujian yang masih dikoreksi oleh dosen atau corrector. Sistem yang terkomputerisasi dapat menjadi solusi untuk memecahkan permasalahan yang ada. Peneliti bermaksud merancang online examination system berbasis web untuk membantu proses penyelenggaraan ujian yang diselenggarakan di Universitas Klabat. Adapun proses model modified waterfall yang digunakan peneliti untuk merancang sistem yang dibuat. Hasil akhir dari penelitian yaitu dapat memudahkan proses pemeriksaan ujian karena sistem dapat melakukan pemeriksaan ujian secara otomatis.
\end{abstract}

\section{Kata kunci : Ujian Online, Aplikasi Web, Proses Model Modified Waterfall}

\begin{abstract}
Paper, pencil, or pen are commonly used for exam purposes in education area. Paper and stationery usage take a great amount of cost and time when organizing an exam, that is the production of question items as well as the processing of the exam result. Another problem faced is the increase of paper consumption globally per year. Klabat University is one among universities that are still using the conventional way of organizing an exam, that is the examination system corrected by the lecturer or corrector. A computerized system can be a good solution to solve the existing problems. Researchers intend to design an online examination system based on web application to help examination processes at Klabat University. Modified waterfall model are used by researchers to design the proposed system. The resulting research could help examination processes by automatically examine an exam.
\end{abstract}

\section{Keywords : Online Exam, Web Application, Modified Waterfall Process Model}

\section{PENDAHULUAN}

$\mathrm{P}$ enggunaan kertas sebagai media pencatatan maupun perekaman

data sering digunakan pada bidang manapun. Pada bidang pendidikan, kertas dan alat tulis berupa pensil dan pulpen digunakan dalam pengerjaan ujian. Namun metode ujian dengan menggunakan kertas dan alat tulis masih bersifat konvensional, sehingga memakan biaya serta durasi yang lama. Konsumsi kertas secara global meningkat $400 \%$ selama 40 tahun terakhir [1], dimana hal tersebut dapat mengancam kerusakan ekosistem dengan meningkatnya jumlah pohon yang ditebang. Melalui masalah yang telah diuraikan, sistem komputer dapat digunakan sebagai media alternatif yang dapat mempermudah penyelenggaraan dan pemeriksaan ujian.

Sistem ujian berbasis komputer yang terintegrasi online lebih dipilih peserta ujian dibanding sistem ujian yang bersifat konvensional [2]. Hal tersebut disebabkan oleh kejelasan teks dan gambar yang ditampilkan, 
serta pemutaran video yang tidak dapat diimplementasikan pada sistem ujian konvensional. Sistem ujian berbasis komputer dapat mengurangi tingkat kecurangan yang dilakukan oleh peserta ujian [3].

Berdasarkan observasi peneliti, Universitas Klabat merupakan institusi pendidikan yang masih menerapkan sistem ujian konvensional, dimana pemeriksaan ujian masih dilakukan oleh dosen atau corrector dari suatu mata kuliah. Sistem tersebut dapat menimbulkan masalah berupa kesalahan pemeriksaan hasil ujian, hilangnya data ujian, serta lambatnya feedback yang diperoleh peserta ujian. Dibutuhkan sistem ujian berbasis komputer yang dapat menyimpan data ujian dengan aman dan terstruktur, serta menyajikan data berupa hasil ujian secara cepat dan tepat.

Oleh karena itu, peneliti bermaksud merancang aplikasi web yang dapat mengatasi permasalahan yang dihadapi pada saat penyelenggaraan ujian di Universitas Klabat. Peneliti menggunakan aplikasi web karena sistem ujian online (online examination system) terbukti efektif diterapkan pada institusi pendidikan lainnya [4]. Tujuan dari penelitian adalah merancang sistem ujian online berbasis web yang dapat digunakan mahasiswa dan dosen di Universitas Klabat.

\section{METODE PENELITIAN}

Pengembangan online examination system berbasis web di Universitas Klabat menggunakan proses model Rekayasa Perangkat Lunak (RPL), yaitu model Waterfall. Model waterfall sering disebut dengan classic life cycle [5]. Proses model Waterfall paling umum digunakan dalam pengembangan perangkat lunak, model ini diperkenalkan oleh Winston W. Royce diawal tahun 1970 [6]. Proses model ini digambarkan dalam bentuk waterfall, karena pengembangannya yang harus sistematis dari satu tahap ke tahap lain. Setiap tahap yang dilalui harus menunggu selesainya tahap sebelumnya. Gambar 1 menjelaskan proses model waterfall yang sistematis melalui tahapan yang diawali dengan Communication untuk mengumpulkan informasi, Planning untuk menentukan sumber daya dan scheduling, Modeling yaitu melakukan proses analisis dan desain sistem, Construction yaitu penulisan kode, pengujian, serta pembuatan dokumentasi, dan tahap akhir yaitu Deployment yaitu penyerahan dan pemeliharaan sistem [5].

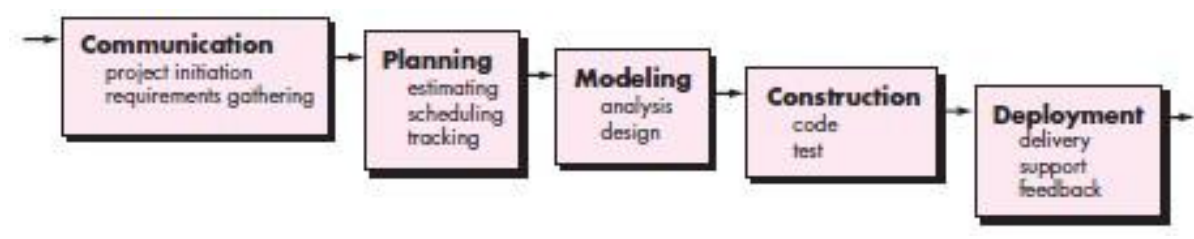

Gambar 1 Proses Model Waterfall [5]

\subsection{Kerangka Konseptual Penelitian}

Kerangka konseptal penelitian menjelaskan setiap proses yang dilakukan dalam penelitian berdasarkan proses model Waterfall, yaitu dengan menggunakan model Modified Waterfall seperti pada Gambar 2.

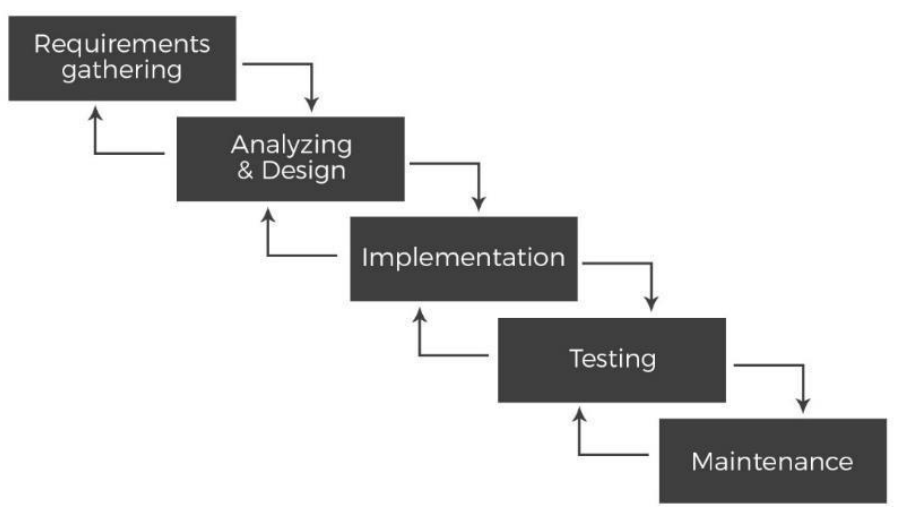

Gambar 2 Kerangka Konseptual Penelitian 
Tahapan penelitian menggunakan model Modified Waterfall dijelaskan sebagai berikut:

\section{Requirements Gathering}

Pada tahap ini peneliti mengumpulkan data primer melalui wawancara yang dilakukan untuk mengetahui kebutuhan pengguna dan pengumpulan data sekuder melalui studi literatur yang berkaitan dengan penelitian.

\section{Analyzing and Design}

Tahap ini peneliti melakukan analisis untuk menentukan kebutuhan dari sistem, dan perancangan sistem berupa cara kerja sistem, rancangan antarmuka, dan perancangan sistem database.

\section{Implementation}

Tahap ini yaitu hasil analisa dan perancangan diimplementasikan menjadi sistem yang dapat berjalan sesuai dengan tujuan dari penelitian.

\section{Testing}

Pada tahapan ini peneliti melakukan pengujian terhadap sistem apakah sudah sesuai atau belum.

\section{Maintenance}

Tahapan ini berkaitan dengan pemeliharaan sistem berupa pengontrolan sistem dan memperbaiki bug.

\subsection{Instrumentasi Penelitian}

Peneliti menjelaskan tentang data yang dikumpulkan, teknik pengumpulan data, dan perangkat lunak yang digunakan dalam perancangan online examination system berbasis web yang dapat diterapkan di Universitas Klabat.

\subsubsection{Jenis Data}

Pada penelitian online examination system berbasis web, terdapat dua jenis pengumpulan data yang dilakukan peneliti, yaitu data primer dan sekunder. Data primer merupakan data yang diperoleh secara langsung, peneliti memperoleh data primer melalui wawancara yang dilakukan kepada mahasiswa dan dosen di Universitas Klabat. Peneliti memperoleh data sekunder melalui hasil penelitian yang sudah pernah dilakukan sebelumnya, jurnal yang telah dipublikasi, buku, dan sumber ilmiah lainnya.

\subsubsection{Perangkat Lunak untuk Pengembangan Aplikasi}

Peneliti menggunakan perangkat lunak dalam perancangan website online examination system yaitu sebagai berikut:

1) Microsoft Windows 1064 bit.

2) PHP 7, sebagai bahasa pemrograman dalam pembuatan web.

3) Xampp v3.3.2.2, sebagai aplikasi untuk menjalankan database MySQL dan web server Apace.

4) Microsoft Visio, untuk pembuatan diagram UML.

5) Bootstrap, sebagai framework HTML, CSS, dan Javascript.

6) Google Chrome v70.0.35.38.77, untuk melakukan pengujian website.

7) Atom v1.32.1, sebagai teks editor.

8) Codeigniter, sebagai framework bahasa pemrograman PHP untuk pengembangan website. 


\subsection{Analisa Sistem}

Peneliti menggunakan Unified Modeling Language (UML) yaitu Use Case Diagram dan Class Diagram. Use Case Diagram menjelaskan mekanisme sistem yang melibatkan pengguna (aktor) [7]. Sedangkan Class Diagram menjabarkan bagian dalam sistem yaitu atribut, method, class, serta access modifiers.

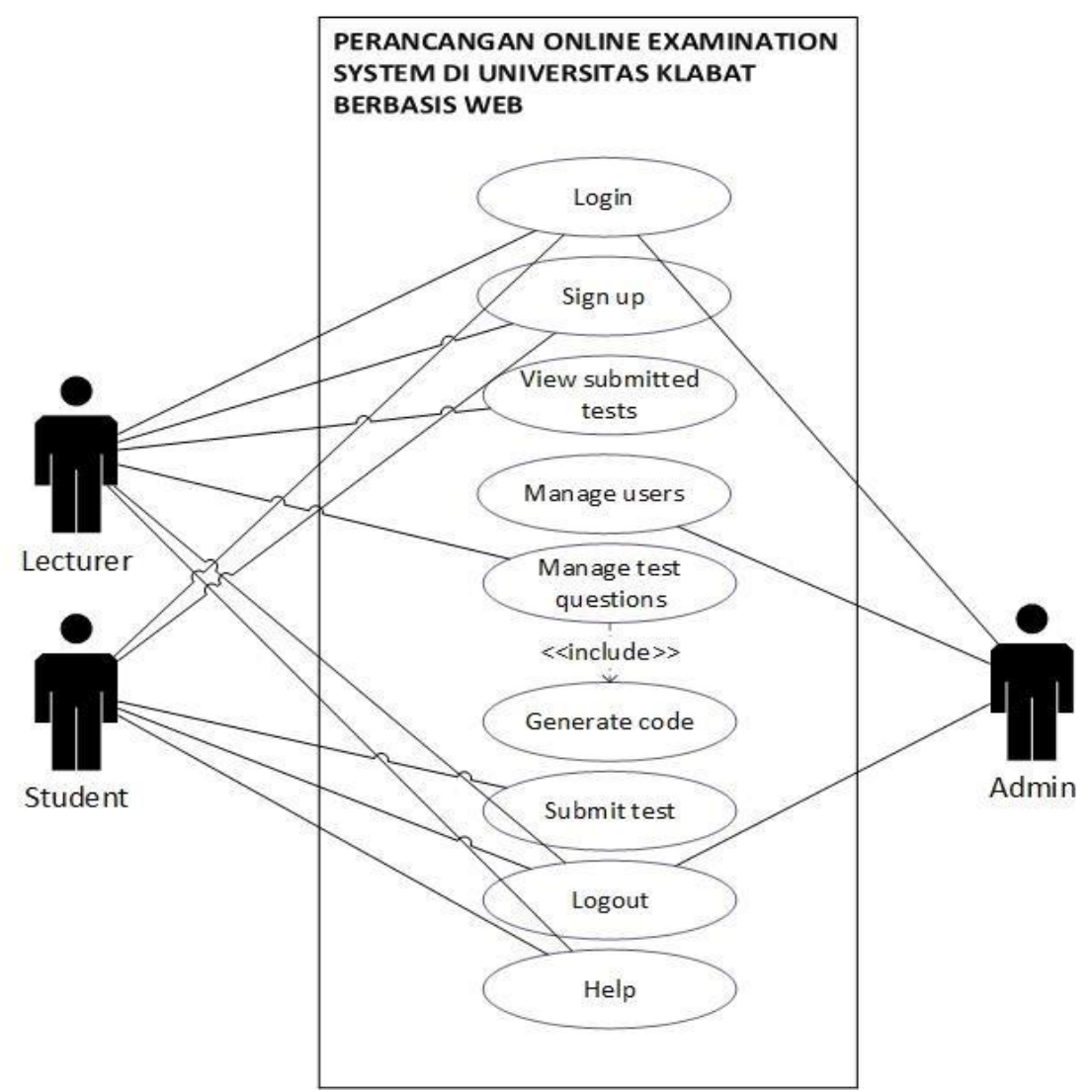

Gambar 3 Use Case Diagram Online Examination System Universitas Klabat

Gambar 3 menjelaskan bagaimana setiap pengguna mengakses setiap fungsionalitas pada online examination system. Aktor yang terlibat yaitu lecturer (dosen), student (mahasiswa), dan admin. Semua aktor dapat mengakses fungsi Login dan Logout. Selain itu aktor lecturer dan student dapat mengakses fungsi Sign Up dan Help. Untuk fungsi View Submitted Tests dan Manage Test Questions hanya dapat diakses oleh aktor lecturer. Use Case Manage Test Questions memerlukan Use Case Generate Code untuk menjalankan fungsinya.

Fungsi Submit Test hanya dapat diakses oleh aktor student. Sedangkan fungsi Manage Users hanya dapat diakses oleh admin. 


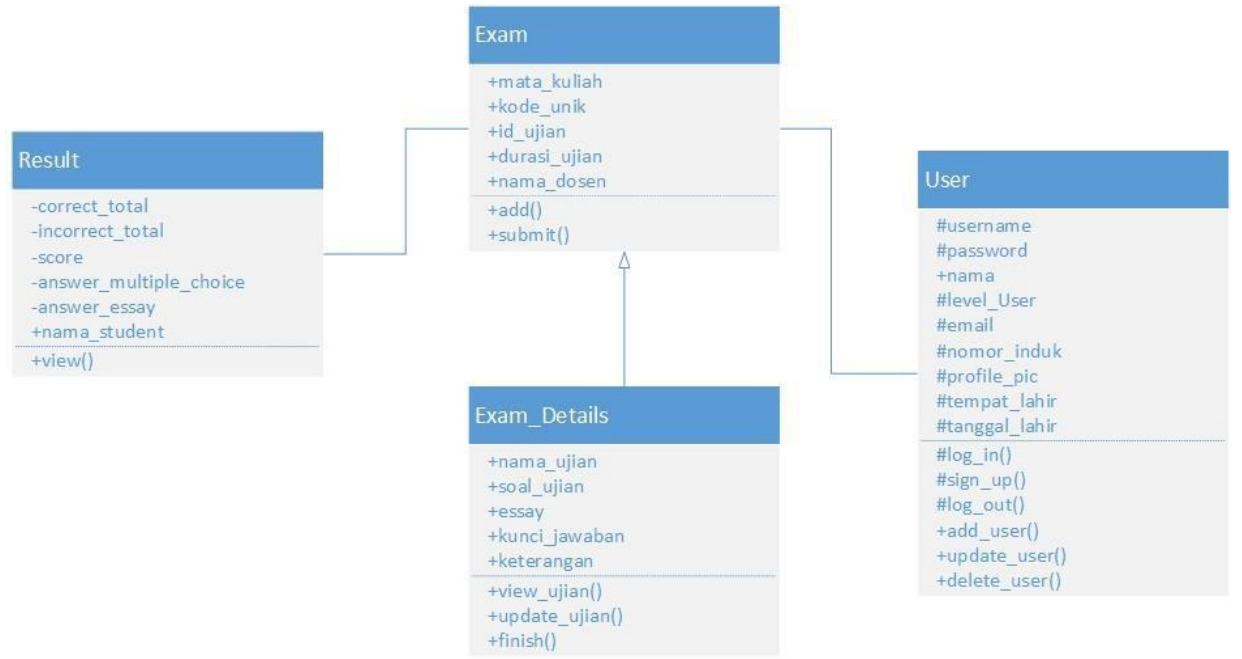

Gambar 4 Class Diagram Online Examination System Universitas Klabat

Gambar 4 menjelaskan Class Diagram online examination system. Terdapat empat Class yaitu Result, Exam, Exam_Details, dan User. Class Result memiliki relasi dengan Class Exam. Class Exam memiliki Class turunan yaitu Exam_Details. Class Exam memiliki relasi dengan Class User. Setiap Class memiliki atribut dan method dengan access modifier yang bervariasi.

\subsection{Implementasi Software}

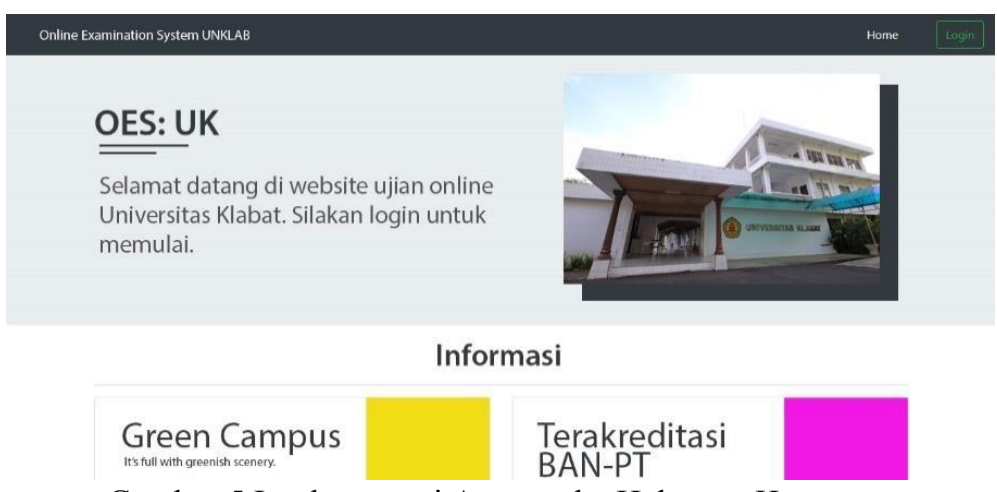

Gambar 5 Implementasi Antarmuka Halaman Home

Gambar 5 merupakan tampilan halaman Home dari web yang dirancang, dimana pengguna dapat melihat informasi mengenai Universitas Klabat, membuat akun student atau lecturer, serta melakukan login ke sistem melalui tombol Login.

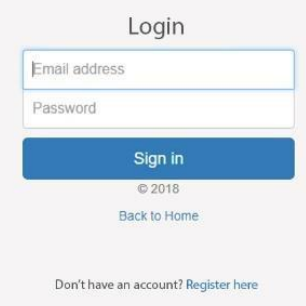

Gambar 6 Implementasi Antarmuka Halaman Login 
Gambar 6 adalah antarmuka halaman Login, dimana pengguna dapat melakukan login ke sistem dengan mengisi email dan password, kemudian memilih tombol Sign In. Adapun link Back to Home untuk kembali ke halaman home, dan link Register here untuk membuat akun.

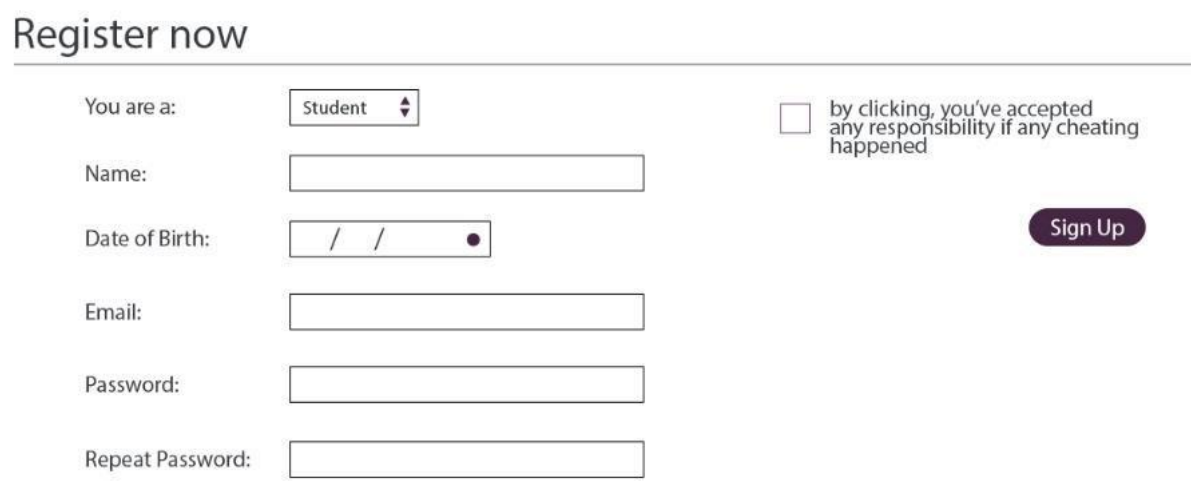

Gambar 7 Implementasi Antarmuka Halaman Register

Pengguna dapat membuat akun yang digunakan untuk masuk ke sistem dengan memilih tipe pengguna, yaitu student atau lecturer, sebagaimana ditampilkan pada Gambar 7. Adapun field yang perlu diisi yaitu nama, tanggal lahir, email, password, dan repeat password. Setelah mengisi semua field, pengguna diharuskan memilih checkbox yang menandakan bahwa pengguna tersebut setuju dengan konsekuensi yang akan diterima apabila terjadi tindak kecurangan selama menggunakan sistem ujian online. Tombol Sign Up dipilih untuk membuat akun.

\section{Admin Dashboard}

Administrator Admin Manage Users

\begin{tabular}{|l|l|}
\hline No & Last Name \\
\hline 1 & Anwar \\
\hline 2 & Aruperes \\
\hline 3 & Barani \\
\hline 4 & Dajoh \\
\hline 5 & Korompis \\
\hline 6 & Mananta \\
\hline 7 & Maramis \\
\hline 8 & Maringka \\
\hline
\end{tabular}

\begin{tabular}{l} 
First Name Gender \\
\hline Roni \\
\hline Cristian \\
\hline Jevon \\
\hline Billy \\
\hline Evan \\
\hline Aldo \\
\hline Miguel \\
\hline Rodney
\end{tabular}

\begin{tabular}{|l|l|}
\hline Email & Action \\
\hline roni@gmail.com & edit update \\
\hline cristian@gmail.com & edit update \\
\hline jevon@gmail.com & edit update \\
\hline billy@gmail.com & edit update \\
\hline evan@gmail.com & edit update \\
\hline aldo@gmail.com & edit update \\
\hline miguel@gmail.com & edit update \\
\hline rodney@gmail.com & edit update \\
\hline
\end{tabular}

Gambar 8 Implementasi Antarmuka Halaman Manage Users

Gambar 8 adalah tampilan antarmuka halaman Manage Users, dimana halaman ini hanya dapat diakses oleh admin. Fungsi yang dapat dilakukan pada setiap pengguna berupa view, edit, serta update. 


\section{Lecturer Dashboard}

\section{Create Exam}

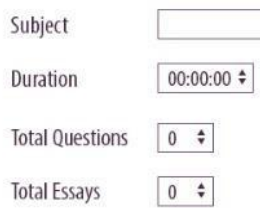

Gambar 9 Implementasi Antarmuka Halaman Create Exam

Lecturer dapat membuat suatu ujian dengan memilih menu Create Exam sebagaimana dijelaskan pada Gambar 9. Pada halaman ini terdapat form yang terdiri dari beberapa field, yaitu subject, duration, total questions, dan total essays. Lecturer dapat memilih tombol next untuk memulai pengisian soal ujian dengan jumlah soal sesuai dengan field yang telah diisi, kemudian melihat unique code yang akan diberikan pada student untuk memulai ujian yang telah dibuat.

\section{Online Examination System UNKLAB \\ Dashboard Create Exam Submitted Help Legat}

\section{Lecturer Dashboard}

Reymon R. Lecturer

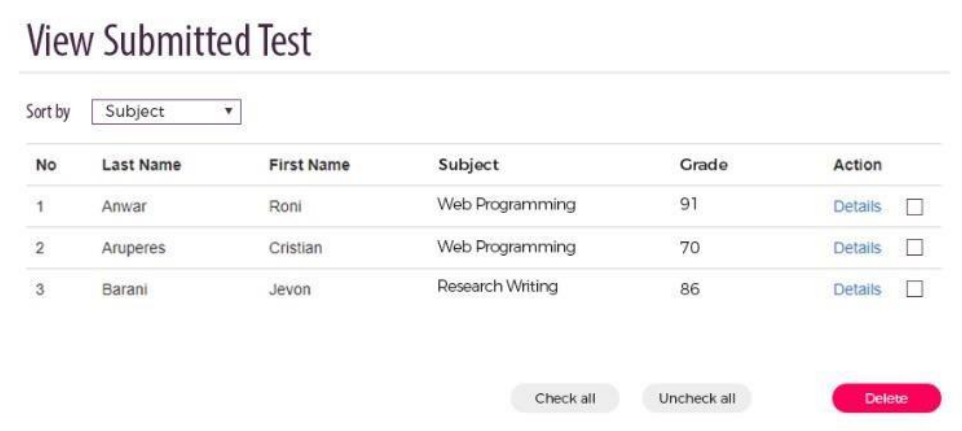

Gambar 10 Implementasi Antarmuka Halaman Submitted

Gambar 10 adalah halaman yang menampilkan daftar student yang telah mengerjakan ujian yang telah dibuat sebelumnya. Pada daftar tersebut, kolom yang ditampilkan adalah no, last name, first name, subject, grade, dan action. Lecturer dapat melihat rincian informasi dari setiap hasil ujian student melalui link Details, dan menghapus data hasil ujian melalui tombol Delete. 


\title{
Student Dashboard
}

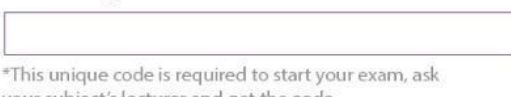

Student dapat memulai ujian setelah melakukan input berupa unique code yang diperoleh dari lecturer. Gambar 11 merupakan tampilan sebelum mengerjakan ujian, dimana field unique code harus diisi oleh student.

Online Examination System UNKLAB

\section{Student Dashboard}

Jevon Barani Student

\author{
Research Writing (A) \\ Test\# \\ Question 1 \\ Berikut merupakan hal-hal yang tergolong dalam makna denotatif, kecuali... \\ Skripsi $\quad$ Puisi Jurnal $\quad$ Memo
}

Gambar 12 Implementasi Antarmuka Pengerjaan Ujian

Gambar 12 merupakan tampilan halaman pengerjaan ujian, dimana halaman ini ditampilkan setelah unique code telah diisi oleh student pada halaman Exam. Sistem secara otomatis akan menampilkan subjek serta soal ujian yang berkaitan dengan unique code tersebut. Tombol Next digunakan untuk melihat dan menjawab soal berikutnya, sedangkan tombol Finish dipilih untuk menyelesaikan ujian dan akan ditampilkan apabila student berada pada tampilan soal terakhir. 
Online Examination System UNKLAB

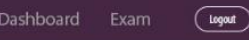

\section{Student Dashboard}

O. Jevon Baran

Result

Congratulations! you've completed the test, here's a brief result of

your test:

Score $86 / 100$

Subject ResearchWriting (A)

Duration $\quad 01: 02: 30$

Gambar 13 Implementasi Antarmuka Hasil Ujian

Student dapat melihat hasil ujian setelah memilih tombol Finish pada saat mengerjakan ujian. Gambar 13 adalah tampilan hasil ujian yang diperoleh oleh student, dimana terdapat skor, subjek, dan durasi dari ujian yang telah diselesaikan. Hasil ujian ini dapat dicetak oleh student melalui tombol Print.

\subsection{Pengujian}

Peneliti menggunakan metode black box untuk menguji online examination system Universitas Klabat. Diperoleh hasil pengujian pada Tabel 1 bahwa aplikasi web yang dibuat telah memenuhi seluruh kriteria.

Tabel 1 Pengujian Aplikasi Web Menggunakan Black Box

\begin{tabular}{|c|c|c|c|}
\hline Nama & Input & Output & Berhasil \\
\hline OES 1 & Login & $\begin{array}{c}\text { Pengguna berhasil masuk } \\
\text { ke dalam sistem }\end{array}$ & Ya \\
\hline OES 2 & Sign Up & $\begin{array}{c}\text { Pengguna berhasil } \\
\text { melakukan pendaftaran } \\
\text { akun }\end{array}$ & Ya \\
\hline OES 3 & View Submitted Test & $\begin{array}{c}\text { Menampilkan daftar } \\
\text { student yang telah } \\
\text { menyelesaikan } \\
\text { ujian }\end{array}$ & Ya \\
\hline OES 4 & View Users & $\begin{array}{c}\text { Menampilkan daftar } \\
\text { pengguna (student/lecturer) }\end{array}$ & Ya \\
\hline OES 5 & Create Exam & $\begin{array}{c}\text { Lecturer berhasil membuat } \\
\text { ujian }\end{array}$ & Ya \\
\hline OES 6 & Generate Code & $\begin{array}{c}\text { Sistem secara otomatis } \\
\text { menghasilkan kode unik } \\
\text { ujian }\end{array}$ & Ya \\
\hline OES 7 & Submit Test & $\begin{array}{c}\text { Student mengirim ujian } \\
\text { yang telah selesai } \\
\text { dikerjakan }\end{array}$ & Ya \\
\hline OES 8 & Edit Users & Mengubah data pengguna & Ya \\
\hline OES 9 & Delete Users & Menghapus pengguna & Ya \\
\hline & & \multicolumn{2}{|c|}{} \\
\hline
\end{tabular}




\begin{tabular}{|c|c|c|c|}
\hline Nama & Input & Output & Berhasil \\
\hline OES 10 & Help & $\begin{array}{c}\text { Menampilkan petunjuk } \\
\text { penggunaan sistem }\end{array}$ & Ya \\
\hline OES 11 & Print Result & $\begin{array}{l}\text { Student mencetak hasil } \\
\text { ujian }\end{array}$ & Ya \\
\hline OES 12 & Logout & $\begin{array}{c}\text { Pengguna berhasil keluar } \\
\text { dari sistem }\end{array}$ & Ya \\
\hline
\end{tabular}

\section{KESIMPULAN}

Berikut ini adalah kesimpulan dari penelitian yang telah dilakukan:

- Website online examination system dapat digunakan sebagai pengganti sistem ujian konvensional yang masih diterapkan di Universitas Klabat.

- Dengan adanya website online examination system, dapat mempermudah dosen dalam memberikan ujian dan mengelola hasil ujian di Universitas Klabat.

- Website online examination system Universitas Klabat dapat memudahkan mahasiswa dalam mengerjakan ujian, karena dapat diakses dimana saja.

- Website online examination system Universitas Klabat memberikan data berupa hasil ujian (feedback) secara cepat dan tepat kepada mahasiswa.

\section{SARAN}

Saran bagi pengembangan selanjutnya berdasarkan hasil penelitian ini, antara lain:

- Menambahkan fitur untuk mengirimkan hasil ujian student kepada orang tua atau wali.

- Menambahkan fitur download report untuk semua ujian yang pernah dikerjakan.

\section{DAFTAR PUSTAKA}

[1] Wallace, C., 2017, The Impact of Paper Consumption on the Environment, https://www.formaliti.com/the-impact-of-paper-consumption-on-the-environment, diakses tgl $17 \mathrm{Mei}$ 2019.

[2] Septanto, H., 2014, Studi Komparasi Antara Media Evaluasi Berbasis Multimedia dengan Media Evaluasi Berbasis Kertas Terhadap Hasil Ujian Pengenalan TIK pada Peserta Pelatihan Kejuruan Operator Komputer di PPKD Jakarta Timur, Bina Insani ICT Journal, No.1, Vol.1, 114, :http://ejournal-binainsani.ac.id/index.php/BIICTJ/article/view/67/64.

[3] Parwati, A., 2012, Analisis dan Perancangan Sistem Ujian Online pada Pelajaran TIK di Sekolah Menengah Pertama 1 Tawangmangu, Jurnal Ilmiah DASI, :http://repository.amikom.ac.id/files/NASKAH\%20PUBLIKASI_10.21.0543.pdf.

[4] Saraswati, N. W. S. dan Putra, D. M. D. U., 2015, Sistem Ujian Online Berbasis Website, Jurnal S@CIES, No.1, Vol.6, 21-30,

:https://ejournal.stikiindonesia.ac.id/index.php/sacies/article/download/78/32.

[5] Pressman. R.S., 2010, Software Engineering: A Practicioner's Approach, Ed.7, McGrawHill, New York.

[6] Matkovi, P. dan Tumbas. P., 2010, A Comparative Overview of the Evolution of Software Development Models, International Journal of Industrial Engineering and Management (IJIEM), No.4, Vol.1, 163-172. 
[7] Reymon. R., 2018, Pengembangan Sistem E-Skripsi Fakultas Ilmu Komputer Universitas Klabat, CogITo Smart Journal, No.1, Vol.4, 72-85,

:http://cogito.unklab.ac.id/index.php/cogito/article/view/103/72. 